Article

\title{
The Challenges and Strategies of Food Security under Rapid Urbanization in China
}

\author{
Yong-sheng Wang ${ }^{1,2}$ \\ 1 Key Laboratory of Regional Sustainable Development Modeling, Institute of Geographic Sciences and \\ Natural Resources Research, Chinese Academy of Sciences, Beijing 100101, China; wangys@igsnrr.ac.cn \\ 2 Center for Assessment and Research on Targeted Poverty Alleviation, Chinese Academy of Sciences, \\ Beijing 100101, China
}

Received: 30 November 2018; Accepted: 18 January 2019; Published: 21 January 2019

\begin{abstract}
Food security has received wide attention in China for a long time due to the challenges of a huge population and limited farmland area. Under conditions of rapid urbanization, the food scenario has changed, creating major challenges for massive populations in China. This paper intends to reveal the impact of urbanization on food security and to propose strategies for mitigating the threats to it. Total grain production has continuously increased, but most of the grain production has been distributed in the northern region since 2006. Although the per capita rural income has increased significantly since 1980, the agricultural income ratio has consistently declined from $56.13 \%$ in 1983 to $26.61 \%$ in 2012. A dramatic shift in food consumption away from grain towards meat, poultry, eggs, milk and liquor has been found in both rural and urban areas. The faster agricultural water consumption growth in northern China over southern China helped close the gap. There has been net increase of cultivated land in northern China, whereas southern China has seen a net decrease. The medium- and low-level cultivation ratios of land were $52.84 \%$ and $17.69 \%$, respectively, in 2015. This paper concluded that food security in China could be ensured by increasing production and optimizing consumption. It suggested that enhanced grain production capacity, strict water management, and land consolidation engineering as well as agricultural industrialization could be used for maintaining grain production. Food consumption itself can be managed by optimizing resident dietary pattern, reducing food waste, adjusting grain consumption structure and moderating food imports policy.
\end{abstract}

Keywords: food security; rapid urbanization; grain production; food consumption patterns; food policy

\section{Introduction}

Rural residents are attracted by the superior public services, cultural facilities, convenient infrastructures and increased opportunities in cities. Massive rural labor shifts out of agriculture and into urban areas enlarge the size of the urban population [1]. From 1978 to 2016, China's urbanization rate increased from $17.91 \%$ to $57.35 \%$ [2], reflecting a growth twice as fast as the world average for the same period. While China is experiencing unprecedented urbanization, a variety of problems have also appeared. Obvious disparities between the highly urbanized east and the less urbanized inland exist [3]. Another important issue is food security coming from changed grain production and food consumption.

Food security has been defined as the state in which all people, at all times, have physical, social and economic access to sufficient, safe and nutritious food that meets both their dietary needs and food preferences for an active and healthy life [4]. Food security is usually referred to as grain 
self-sufficiency in China [5]. Grains provide the main sources of human food, animal foodstuffs and raw materials for processed food products and thus are essential to food security in China.

China, with about $20 \%$ of the global population, has only about $6 \%$ and $8 \%$ of world's water resources and cultivated land, respectively. Brown presented the doubt of who will feed China [6]. Although, there were more pessimistic predictions about China's food security, China's governments have committed to feed its growing population $[7,8]$. The government has taken a series of strong policy measures to ensure food security. Rural institutional innovation, agricultural technology change, market reform, and increased investment in agriculture are the four major driving factors in China's agricultural growth and food security [8]. Grain self-sufficiency has been the government's concern in the past several decades [8]. Complete self-sufficiency in grain was China's goal before the mid-1990s. With increasing food demand and given the land and water constraints, the grain self-sufficiency level has been targeted at $95 \%$ or higher since 1996. A policy of "four reductions and four subsidies" was carried out to encourage grain production from 2004 [9]. Ensuring largely self-sufficiency in cereal and absolute security in rice and wheat (kouliang) has become the new and primary national food security goal since 2014 [8]. The role of land production capacity and agricultural technology were emphasized in the recent national food security strategy [9]. In 2015, the twelfth consecutive increase in total grain output effectively ensured food security for China. With the rapid economic growth, China's food supply chain efficiency and food safety is important to global food security [10]. However, some new issues like rapid economic development, global change, environmental protection and resources sustainable utilization will continue to add new constraints to current food security. Therefore, it is necessary to point out the challenges of food security.

Urbanization has further worsened China's urgent situation of food security. Along with rapid urbanization and city sprawl, grain production is drastically affected by the decline in the quantity and quality of land, water shortages, and the departure of agricultural labor [11-13]. Wang et al. found that urban expansion resulted in the rapid decline of agricultural land [13]. Deng et al. used land-use remote sensing data to indicate that China's developed eastern region loss cultivated land by $7 \%$ and $29.2 \%$ during 1995-2000 and 2000-2008, respectively [14]. Potential crop yield has decreased by approximately 34.90 million tons due to urban expansion, accounting for $6.52 \%$ of China's total actual production during 1990-2010 [15]. Huang-Huai-Hai Plain is one of the key areas of lost potential yield due to conversion of fertile and irrigated land to non-agricultural uses under rapid urbanization [16]. Even so, northern China gradually became the gravity center of grain-output due to the overdevelopment and utilization of groundwater in north China [17]. Therefore, the variations of grain production and agricultural water consumption should be noted. In addition, accelerated urbanization also leads to major changes in the levels and patterns of food consumption and in food purchasing behavior $[10,18]$. With increasing incomes, people not only tend to increase their food intake, but also begin to move up the food chain, from primary products (such as grain, roots, or pulses) to secondary food commodities (such as meat, fish and milk) [12]. China's more livestock-based food consumption patterns put more pressures on the limited cultivated land resources [19]. Therefore, this paper hypothesized that China's historical assumption of food security as grain security is no longer fit for the rapid and expansive urbanization development. This study firstly presented the changed food consumption patterns, environmental pressures on grain production under rapid urbanization, and then proposed a conceptual framework of food security. Although access to food and the stability of food supplies are crucial for food security, our study mainly focuses on tracking the impacts of urbanization on grain production and food consumption.

\section{Data Sources and Methodology}

\subsection{Data Sources}

The data sources used for this study included grain production, income, food consumption, agricultural water consumption, and cultivated land area and quality data. Grain production, income, 
food consumption, agricultural water consumption and cultivated land area data were collected from the National Bureau of Statistics of China (http://www.stats.gov.cn/tjsj/ndsj/). Cultivated land quality data were collected from the Land Resources Bulletin (http://www.mnr.gov.cn/sj/). All the province data did not include Hong Kong, Macao and Taiwan.

\subsection{Methodology}

Northern China is defined by the line formed by the Huai River and Qingling Mountain range. Jiangsu and Anhui provinces are divided into southern China. Grain production, agricultural water consumption and cultivated land area of northern and southern China is summed over 15 and 16 provinces, respectively. The agricultural income ratio is obtained by dividing the average household agricultural income of rural residents by the average household income of rural residents.

\section{Results}

\subsection{Grain Production}

After grain production reached its first historical high in $1998\left(51,230 \times 10^{7} \mathrm{~kg}\right)$, it decreased to $43,070 \times 10^{7} \mathrm{~kg}$ in 2003, increased in successive years, and achieved 60,703 $\times 10^{7} \mathrm{~kg}$ in 2014 (Figure 1a). The production gaps between northern and southern China have decreased since 2001, although the faster grain production growth in northern and southern China did increase the production gap from its lowest value of $486 \times 10^{7} \mathrm{~kg}$ in 2006 to $7752 \times 10^{7} \mathrm{~kg}$ in 2016 (Figure 1b).
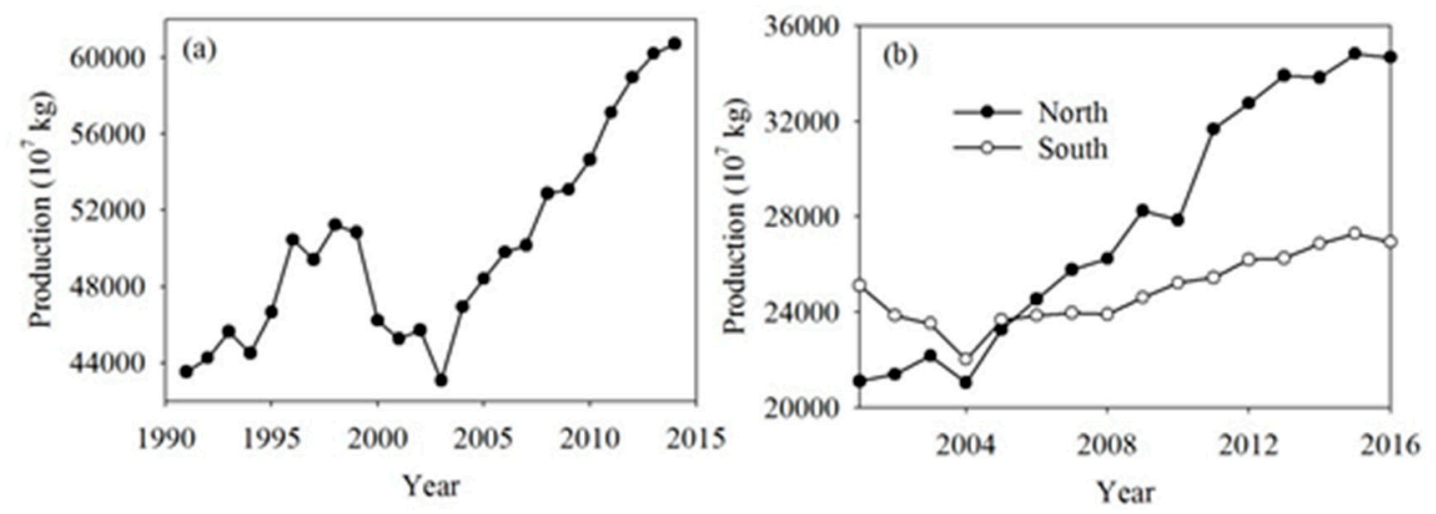

Figure 1. Grain production for China overall and northern and southern regions: (a) Overall grain production; (b) Grain production of northern and southern regions.

\subsection{Changing Consumption Patterns}

The per capita rural income increased up to 58.26 times from its lowest value of 133.6 Yuan in 1980 to 7916.16 Yuan in 2012 (Figure 2a). However, the agricultural income ratio has consistently declined from $56.13 \%$ in 1983 to $26.61 \%$ in 2012 (Figure 2b). Food consumption patterns between rural and urban residents changed significantly after reform and liberalization policies, with an increased consumption of meat, poultry, eggs, milk and liquor, and a reduced consumption of grain (Figure 2c,d). In 2012, the rural per capita consumption of meat, poultry, eggs, milk and liquor was $16.4 \mathrm{~kg}$, $4.5 \mathrm{~kg}, 5.9 \mathrm{~kg}$, $5.3 \mathrm{~kg}$ and $10.0 \mathrm{~kg}$, respectively, which was 1.13, 5.43, 3.92, 6.57 and 4.26 times higher, respectively, than in 1980 (Figure 2c). However, the per capita consumption among urban residents during the same period was decreasing (Figure 2d). Since the early 2000s, the rural per capita consumption of grain has decreased by $34.33 \%$, while the urban per capita consumption of grain decreased from $127 \mathrm{~kg}$ in 1991 to $63.6 \mathrm{~kg}$ in 2008 (Figure 2c,d). In addition, the quantity of animal products consumed by urban residents is much higher than that consumed by rural residents (Figure $2 \mathrm{c}, \mathrm{d}$ ). 

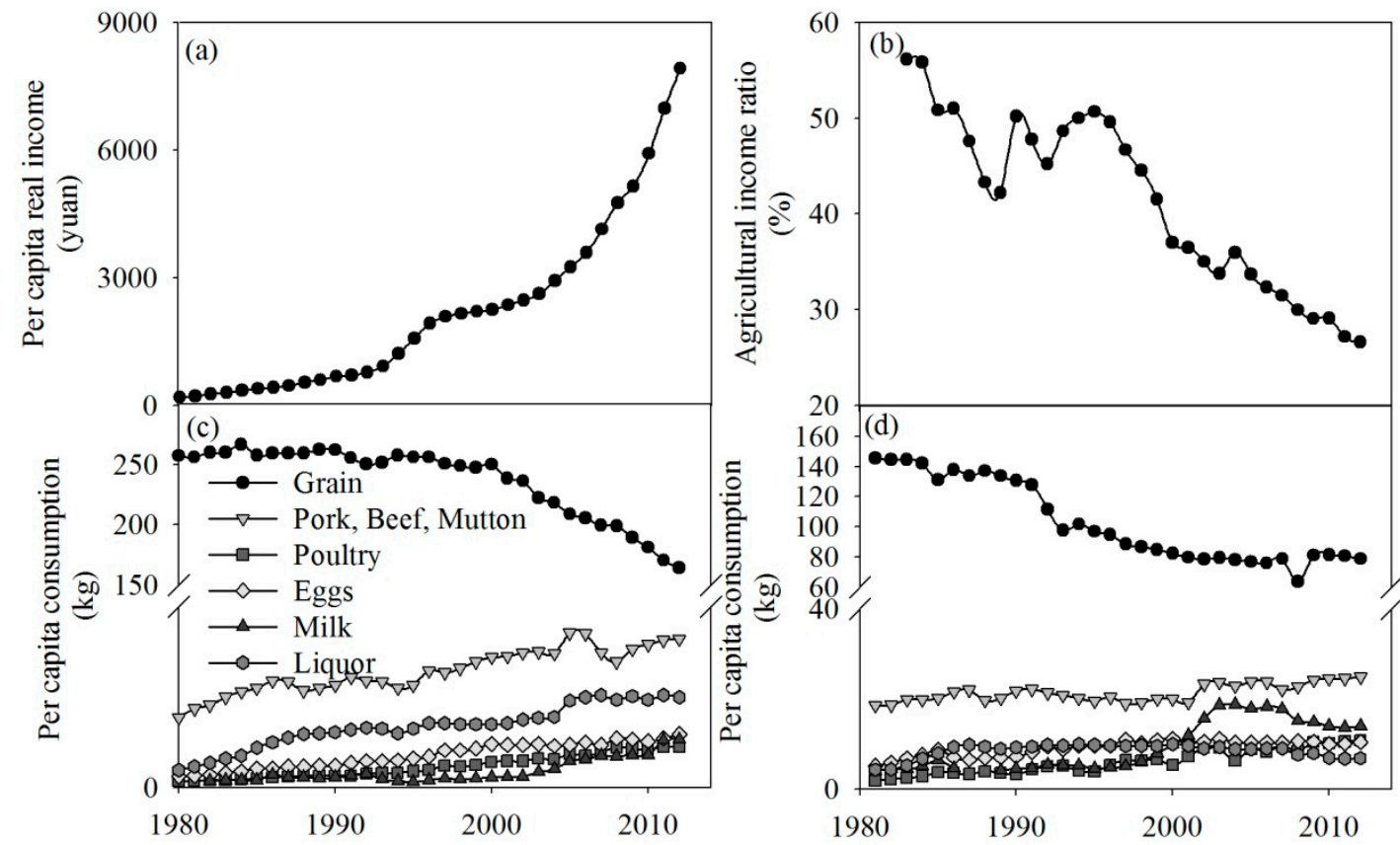

Figure 2. Income and per capita food consumption patterns in China: (a) Per capita rural income; (b) Agricultural income ratio; (c) Rural per capita food consumption; (d) Urban per capita food consumption.

\subsection{Environmental Pressures}

\subsubsection{Agricultural Water Consumption}

Agricultural water consumption increased from $3585.7 \times 10^{8} \mathrm{~m}^{3}$ in 2004 to $3921.5 \times 10^{8} \mathrm{~m}^{3}$ in 2013 , and then it began to slowly decline. By late 2015, agricultural water consumption was approximately $7.41 \%$ higher than that of 2004 (Figure 3a). The patterns of distortions in agricultural water consumption in the northern and southern regions show remarkably similar patterns. The agricultural water consumption gap between northern and southern regions has decreased due to the significantly increased agricultural water consumption in the northern region since 2012 (Figure 3b).
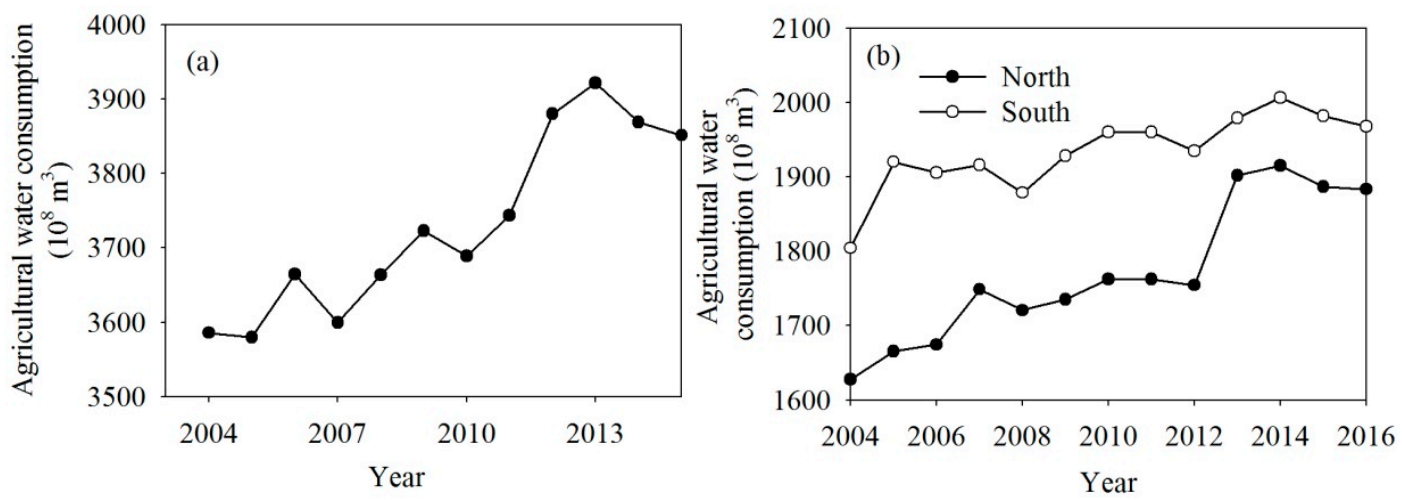

Figure 3. Agricultural water consumption for China overall and northern and southern regions: (a) Agricultural water consumption; (b) Agricultural water consumption of northern and southern regions.

\subsubsection{Cultivated Land Amount and Quality}

After the total cultivated land amount reached the lowest level in 2009, it increased to $13,527 \times 10^{4}$ ha in 2010 . The cultivated land amount in the northern region has significantly increased 
from $7394 \times 10^{4}$ ha to $8046 \times 10^{4}$ ha in 2015 , while cultivated land quantity in the southern region has declined from $5610 \times 10^{4}$ ha to $5454 \times 10^{4}$ ha in 2015 (Table 1 ).

Table 1. Interannual variation of cultivated land areas $\left(10^{4} \mathrm{ha}\right)$.

\begin{tabular}{cccccccccc}
\hline Year & $\mathbf{2 0 0 7}$ & $\mathbf{2 0 0 8}$ & $\mathbf{2 0 0 9}$ & $\mathbf{2 0 1 0}$ & $\mathbf{2 0 1 1}$ & $\mathbf{2 0 1 2}$ & $\mathbf{2 0 1 3}$ & $\mathbf{2 0 1 4}$ & $\mathbf{2 0 1 5}$ \\
\hline Total & 13,004 & 12,174 & 12,172 & 13,527 & 13,524 & 13,516 & 13,516 & 13,506 & 13,500 \\
North & 7394 & 6955 & 6957 & 8060 & 8056 & 8051 & 8050 & 8048 & 8046 \\
South & 5610 & 5218 & 5215 & 5467 & 5468 & 5465 & 5466 & 5458 & 5454 \\
\hline
\end{tabular}

The excellent and high level cultivated land areas totaled $397.38 \times 10^{4}$ and $3584.60 \times 10^{4}$ ha, respectively, and accounted for $2.94 \%$ and $26.53 \%$ of the total cultivated land area. The largest cultivated land area was at the medium level, with $3584.60 \times 10^{4}$ ha and $52.84 \%$ of the total cultivated land area, while $2389.25 \times 10^{4}$ ha, or $17.69 \%$ of the total cultivated land was at the low level (Table 2).

Table 2. Area and ratio of different cultivated land qualities in 2015.

\begin{tabular}{ccccc}
\hline Level & Excellent & High & Medium & Low \\
\hline Area $\left(10^{4}\right.$ ha $)$ & 397.38 & 3584.60 & 7138.52 & 2389.25 \\
Ratio $(\%)$ & 2.94 & 26.53 & 52.84 & 17.69 \\
\hline
\end{tabular}

\section{Discussions}

\subsection{Enhance Grain Production Capacity}

Food production is limited by natural resources, biological species resources, agricultural production materials, technology input, and relevant policy $[8,20]$. Despite the achievement of continuously increased grain production (Figure 1a), annual growth rates of grain production have been gradually slowed [21]. Declining soil quality and inappropriate crop management practices are likely responsible. Excessive fertilizer application has caused varying degrees of soil acidification and ecological degradation to the current arable land resources [22,23]. Moreover, increasing agronomic input has resulted in diminishing returns of land among crops, and thus, yields have stagnated extensively [24]. Therefore, China's food security can be firstly enhanced through protecting existing cultivated land area and improving the land productive. Godfray et al. [25] and Zhang et al. [26] gave the important evidence of huge potential of grain production by closing the yield gap between actual field yield and potential yield.

In recent years, China has issued several new development ideas, in particular "Cang-liang-yu-di" ("food storage in land") and "Cang-liang-yu-ji" ("food storage in technology") [8]. China has also announced a number of significant policy initiatives and plans to improve soil environment and quality, including the "Fertilizer Use Zero Growth Program", the "Soil Pollution Control Plan of Action" and the "Zero Discharge of Agricultural Waste". Cultivated land productivity can be enhanced by high-standards of farmland construction along with farmland rehabilitation of medium and low yields. In addition, innovative agricultural technological approaches play an important role in improving soil quality, increasing resource utilization, and fostering agricultural efficiencies [22]. Closing yield gaps could potentially double global food output, substantially enhancing food security [27]. If Chinese farmers could achieve average grain yields, equivalent to $80 \%$ of the yield using integrated soil-crop system management approaches by 2030, the total production of rice, wheat and maize would be more than enough to meet the demand for direct human consumption, as well as the substantially increased demand for animal feed [21]. According to the Science and Technology Backyard platform established in Quzhou County, a five-year average yield increase from $67.9 \%$ to $97.0 \%$ of the attainable level will achieve yield and economic gains as well as sustainability [26]. Agricultural intensification focused on closing yield gaps is a key to increasing food production. It is noteworthy that due to the seriously 
degraded status of China's natural resources, intensification methodologies must be sustainable and environmentally benign [28].

\subsection{Optimize Dietary Pattern of Residents}

Urbanization affects not only the quantity of foods consumed, but also the composition of the diet. With rapid urbanization, changes in food consumption patterns are driven both by increasing incomes and an improved access to a wider variety of foods [19]. Higher per capita rural income has led to the increased consumption of meat, poultry, eggs and milk, at rates 1.13, 5.43, 3.92 and 6.57 times higher, respectively, more in 2012 than in 1980 (Figure 2a,c). In addition, urban consumers spent approximately $33 \%$ of their total food expenditure on convenience foods that includes more animal foods, vegetables, and edible oils [10,29]. The quantity of animal products consumed in urban areas is double that of rural areas (Figure 2c,d). Processed food and livestock-based food needed the most arable land for production [19]. These results suggested a wider difference in per capita arable land requirements between urban and rural areas. Gerbens-Leenes and Nonhebel [30] revealed that the effects of changes in food consumption patterns on land requirements will be even greater than the growth in the world population. Li [19] reported that each $1 \%$ increase in urbanization would cause a more than 140,000 ha increase in China's arable land requirement. In China, urban populations have increased at nearly three times the rate of rural populations since 1980. The efficiency of converting plant matter into animal matter is approximately $10 \%$. Thus, the increasing urban population and growing demand for animal products will place enormous pressure on grain food production and supplies. Therefore, supplementary farmland resources, new agricultural technology, and substantially better management of natural resources including addressing environmental concerns will produce the additional food to satisfy the consumption requirements.

To alleviate these pressures, increased animal production and improved livestock breeding are needed to supply quality and safe food in sufficient quantities. Feeding more forage to livestock and improving fodder utilization can help save more basic grains for human consumption [31]. The rapid increase of fishery products has eased the pressures on China's land-based animal agriculture somewhat. Sustainable fish farming and marine fish harvesting, along with the protection of endangered marine species, will be key issues for these industries in the future [32]. In addition, the pressure on food security can be lowered by optimizing resident dietary consumption patterns. The Chinese government recommends that approximately $35 \%$ and $27 \%$ of protein should be from livestock-based food in the case of urban residents and rural residents, respectively; however, since 2002, both urban and rural residents have exceeded these recommendations [19,33]. Real per-capita grain consumption in China ranges between 378.88 and $406.09 \mathrm{~kg} \mathrm{yr}^{-1}$, which also exceeds the limits defined by a balanced dietary pattern [34]. Therefore, the government should invest in research related to a reasonable diet structure and guide citizens in the cultivation of reasonable food consumption habits. China promulgated several versions of dietary guidelines and food guide pagoda to educate people in the consumption of a well-balanced diet. The new food guide pagoda was proclaimed in 2016 with five levels. Meat, fish and eggs are the third most important, with a specific daily intake of 40-75 g, 40-75 g and 40-50 g, respectively. The Chinese government has outlined a plan to reduce its citizens' meat consumption by $50 \%$ [35]. These concerns and foresights will support the pathway to enhance China's food security.

\subsection{Sustainable Land and Water Resources Utilization}

Land and water limitations as well as soil fertility issues seriously constrain food availability in China [10]. Urban areas are mostly converted from croplands, leading to the rapid decline of agricultural land $[12,13]$. Urban expansion also accelerates the marginalization of inferior farmland and abandonment of cultivated land due to the rising costs of farming [13,36]. Furthermore, the total pollution rate in Chinese farmland soil is $10.18 \%$, mainly from $\mathrm{Cd}, \mathrm{Hg}, \mathrm{Cu}$, and $\mathrm{Ni}$ [37]. The monitoring results showed that the desertified and sandified areas of China were $261.16 \times 10^{4} \mathrm{~km}^{2}$ 
and $172.12 \times 10^{4} \mathrm{~km}^{2}$ by 2014 , respectively. Areas of medium and low productivity land account for $52.84 \%$ and $17.69 \%$, respectively, of the total cultivated land in China (Table 2). China's agricultural water consumption has greatly increased with the increasing food demand caused by the growing population and rapid urbanization (Figure 3a). Overuse of surface water, declining groundwater levels and water pollution is threatening the sustainability of agricultural production in China [22] The Chinese government has implemented a series of strong policy measures to steadily increase grain production from $43,529 \times 10^{7} \mathrm{~kg}$ in 1991 to $60,703 \times 10^{7} \mathrm{~kg}$ in 2014 (Figure 1a). Strict policies such as the " 1.8 billion mu ( $120 \times 10^{6}$ ha) red line of cultivated land" were initiated in 2006 to ensure food security. The innovation of the cultivated land occupation-compensation balance was implemented to control cultivated land loss. The Chinese government also imposed the "three red line" restriction policy to protect agricultural water resources in 2010.

The north of China, similar in land area and population to the south, holds only $18 \%$ of the total water despite having $65 \%$ of the total arable land [22]. However, the grain production of the northern region has been higher than that of the southern region from 2006 (Figure 1b). Although the newly reclaimed agricultural land offsets the loss created by urban expansion and agricultural abandonment, northern China has seen a net increase in the total area of cultivated land, while southern China has seen a net decrease (Table 1). Significantly increased agricultural water consumption in Northern China (Figure 3b) will exacerbate the mismatch between land and water resources. For example, the North China Plain contains $33.8 \%$ of the national arable land, but has only $3.85 \%$ of the national water resources. Over the past 40 years, the groundwater water table has fallen steadily, as approximately $120 \times 10^{10} \mathrm{~m}^{3}$ more water has been pumped from the land than the amount replaced by rainfall [38]. Consolidation and reclamation of degradation land, unused land, and vacant/idle construction land are hopeful prospects for cultivated land supplementation and protection $[13,39]$. The South-North Water Transfer Project (Nanshui beidiao gongcheng) was adopted to solve the northern China's water scarcity problem. Relevant laws and regulations have also been established to improve water use efficiency and to limit overall demand.

\subsection{Moderate Food Imports Policy}

Over the past few decades, While China's government has been successfully meeting domestic consumption demand with domestically produced food, food imports have become an increasingly important component of China's food security. Various protectionist policies are used to offset the domestic agricultural limitations by moderating imports. China's food imports have been consistently increasing in recent years, accounting for $6.7 \%$ of total merchandise imports [7]. China imports significant quantities of soybeans and oilseeds (US\$11.9 billion) as well as grains and feeds, including corn, wheat, and rice (US $\$ 8.5$ billion) [9]. Pingali [29] suggested that importing food could be relatively easier and less costly than acquiring the same food from the domestic hinterlands, especially for coastal cities such as Shanghai or Guangzhou. In addition, investment in overseas agriculture is used to influence food production and imports. There are over 300 Chinese companies that have invested in agricultural, forestry, and fishing project in 46 countries [40]. The scale and scope of outward foreign direct investment in agriculture will gradually expand. The overseas agriculture strategy has aroused repercussions for global resources. Local resistance frequently occurred due to lacking of corporate social responsibility. Chinese overseas agricultural companies need to show greater commitment to local community's needs and environmental protection as well as host countries' food security [10]. Ali et al. [41] reported that China's food trade has increasingly contributed towards global saving of virtual water and land. Therefore, a carefully designed policy of "mainly depend on domestic production with moderate imports" may help in achieving national food security.

\section{Limitations of This Study}

Urbanization largely depends on the finite natural resources, including land, water and energy. Our study summarized the challenges to food security under rapid urbanization from the aspects of 
grain production and consumption. Competitions from urban and industrial demand may further limit water and land available for agriculture. Rapid growth in food consumption and fundamental transformation in the food system add complexity and pressure to the Chinese food security situation. Other disadvantages including the aging trend in rural labor, food waste in urban areas, and national grain demand, were not discussed. The outflow of the rural labor force has significantly decreased the quality of agricultural laborers due to the lack of middle-aged laborers [42]. These changes have negative effects on the multi-cropping index and grain production. In recent years, the rate of loss for China's grain output has been an estimated $8 \%, 2.6 \%$ and $3 \%$ during storage, processing and distribution, respectively, with a total of 35 million tons lost annually [43]. Gao et al. [44] estimated that food waste in China's provincial capitals was approximately 6 million tons in 2008. Wang [45] also reported that the total amount of food wasted in China's canteens, restaurants and homes across the country could feed 0.3 billion people every year. Due to the increased demand both for animal production and for biomass energy, grain for fodder and for industrial uses has steadily increased. Total grain for fodder and industrial consumption is predicted to reach $27.47 \times 10^{10} \mathrm{~kg}$ and $8.39 \times 10^{10} \mathrm{~kg}$, respectively, by $2020[11,46]$. Thus, a primary model is proposed to meet the challenges to food security under rapid urbanization (Figure 4). However, this paper did not consider the impacts of macroeconomic factors and global shocks on food security. Hammond and Dube [47] outlined a framework for the study of food and nutrition security focused on three major systems: The agri-food system, the environmental system, and the health/disease system. In addition, natural disasters, war and climate change also have devastating effects on food production [40].

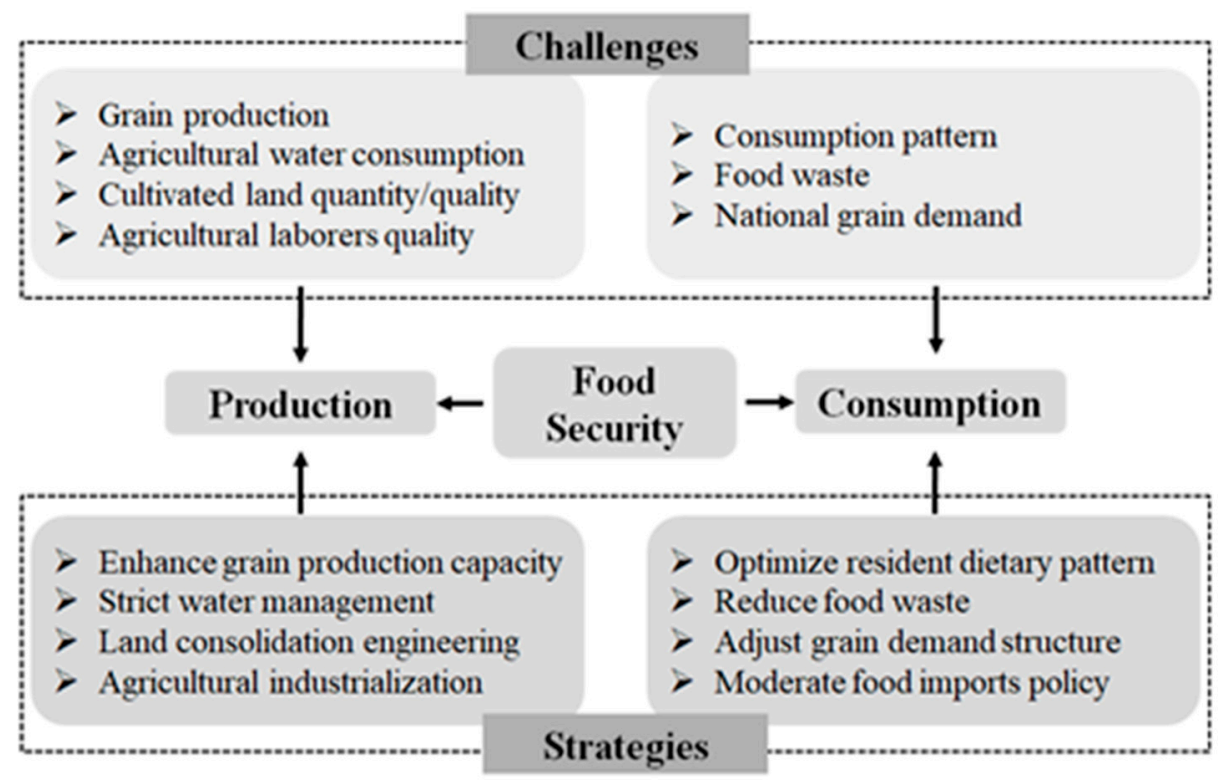

Figure 4. Food security challenges and strategies with rapid urbanization in China.

\section{Conclusions}

This paper firstly analyzed the challenges to food security in China in the context of rapid urbanization. Grain production stability is threatened by a decline in cultivated land (both in amount and quality), a shortage of agricultural water consumption and a decreased agricultural laborers quality due to rapid urbanization. The mismatched water and land resources between northern and southern China will exacerbate this situation. Food security has also been challenged by the changed food consumption and national grain demand pattern as well as food waste.

Challenges of China's food security can be alleviated from the strategies of enhanced food production and optimized food consumption. Firstly, land increasing vs. decreasing balance policy and relevant engineering measures with the idea of the trinity of quantity control, quality management 
and ecological protection can provide the basis of grain production. In addition, agricultural research-education-service-policy input like Science and Technology Backyard platform will close the crop yield gaps to address the challenge of food security. Furthermore, water resource management and protection policy support the guarantee of grain production. Adjusted national grain consuming pattern and reduced food loss and waste will save more grain to satisfy the human demanding. Dietary guidelines and food guide pagoda guide people to cultivate a well-balanced diet with consuming little animal products. Moderate food imports policy may help achieving national food security.

In the future, differentiation of food security strategies should be considered due to China's obvious urbanization development patterns, especially in the eastern coastal regions. Significant differences of land and water resource endowment and diversified economic development orientation also affect grain production capacity and food consumption patterns. Therefore, gravity of grain production and consumption must be emphasized in the further studies. Lastly, other challenges like global change, macroeconomic factors and global shocks should be noted to alleviate the negative effects on food security.

Funding: This project was supported by National Key R\&D Program of China (No. 2017YFC0504701), Key Program of the National Natural Science Foundation of China (No. 41731286); National Natural Science Foundation of China (No. 41801174).

Conflicts of Interest: The author declares no conflict of interest.

\section{References}

1. He, C.F.; Chen, T.M.; Mao, X.Y.; Zhou, Y. Economic transition, urbanization and population redistribution in China. Habitat Int. 2016, 51, 39-47. [CrossRef]

2. National Bureau of Statistical of China. Chinese Statistical Yearbook 2016; China Statistics Press: Beijing, China, 2016.

3. Long, H.L. Land consolidation: An indispensable way of spatial restructuring in rural China. J. Geogr. Sci. 2014, 24, 211-225. [CrossRef]

4. FAO. The State Food Insecur. World. State Food Insecur. World 2001, 316, 3-8.

5. Zhou, J.Y. China and (World) Food Security. Available online: https://www.sipri.org/commentary/blog/ 2016/ china-and-world-food-security (accessed on 16 October 2016).

6. Brown, L.R. Who Will Feed China? Wake-Up Call for a Small Planet; London England Earthscan Publications: London, UK, 1995.

7. FAOSTAT. FAOSTAT Online Database. Available online: http://faostat3.fao.org/home/E (accessed on 21 November 2018).

8. Huang, J.K.; Yang, G.L. Understanding recent challenges and new food policy in China. Glob. Food Secur. 2017, 12, 119-126. [CrossRef]

9. Kuteleva, A. China's Food Security Situation: Key Issues and Implications for Canada (Occasional Paper Series, VOL. 3, No. 1). Unversity of Alberta, Edmonton, Canada. Available online: https://cloudfront.ualberta. ca/-/media/china/media-gallery/research/occasional-papers/food-securityanna-kuteleva201604.pdf (accessed on 21 November 2018).

10. Gandhi, V.P.; Zhou, Z. Food demand and the food security challenge with rapid economic growth in the emerging economies of India and China. Food Res. Int. 2014, 63, 108-124. [CrossRef]

11. Chen, J. Rapid urbanization in China: A real challenge to soil protection and food security. Catena 2007, 69, 1-15. [CrossRef]

12. Li, J.M.; Li, Z.H. Physical limitations and challenges to Grain Security in China. Food Secur. 2014, 6, 159-167. [CrossRef]

13. Wang, C.; Gao, Q.; Wang, X.; Yu, M. Spatially differentiated trends in urbanization, agricultural land abandonment and reclamation, and woodland recovery in Northern China. Sci. Rep. 2016, 6, 37658. [CrossRef]

14. Deng, X.Z.; Huang, J.K.; Rozelle, S.; Zhang, J.P.; Li, Z.H. Impact of urbanization on cultivated land changes in China. Land Use Policy 2015, 45, 1-7. [CrossRef] 
15. Liu, L.; Xu, X.L.; Chen, X. Assessing the impact of urban expansion on potential crop yield in China during 1990-2010. Food Secur. 2015, 7, 1-11. [CrossRef]

16. Shi, W.J.; Tao, F.L.; Liu, J.Y. Changes in quantity and quality of cropland and the implications for grain production in the Huang-Huai-Hai Plain of China. Food Secur. 2013, 5, 69-82. [CrossRef]

17. Wang, J.Y.; Liu, Y.S. The Changes of grain output center of gravity and its driving forces in China since 1990. Resour. Sci. 2009, 31, 1188-1194.

18. Huang, J.K.; Rozelle, S. Market development and food demand in rural China. China Econ. Rev. 1998, 9, 25-45. [CrossRef]

19. Li, G.L. Effects of urbanization on arable land requirements in China, based on food consumption patterns. Food Secur. 2013, 5, 439-449. [CrossRef]

20. Cao, Z.H.; Hao, J.M.; Liang, L.T. Gray Comprehensive Correlation Analysis on Major Grain Output and Input Elements of Huang-Huai-Hai Plain. Res. Agric. Mod. 2008, 29, 310-313.

21. Cheng, G.Q.; Zhang, H.Z. China's Global Agricultural Strategy: An Open System to Safeguard the Country's Food Security; RSIS Working Paper, No. 282; Nanyang Technologies University Press: Nanyang, Sigapore, 2014.

22. Fan, M.S.; Shen, J.B.; Yuan, L.X.; Jiang, R.F.; Chen, X.P.; Davies, W.J.; Zhang, F.S. Improving crop productivity and resource use efficiency to ensure food security and environmental quality in China. J. Exp. Bot. 2012, 63, 13-24. [CrossRef]

23. Guo, J.H.; Liu, X.J.; Zhang, Y.; Shen, J.L.; Han, W.X.; Zhang, W.F.; Christie, P.; Goulding, K.W.T.; Vitousek, P.M.; Zhang, F.S. Significant acidification in major Chinese croplands. Science 2010, 327, 1008-1010. [CrossRef]

24. Foley, J.A.; Ramankutty, N.; Brauman, K.A.; Cassidy, E.S.; Gerber, J.S.; Johnston, M.; Mueller, N.D.; O'Connell, C.; Ray, D.K.; West, P.C.; et al. Solutions for a cultivated planet. Nature 2011, 478, 337-342. [CrossRef]

25. Godfray, H.C.; Beddington, J.R.; Crute, I.R.; Haddad, L.; Lawrence, D.; Muir, J.F.; Pretty, J.; Robinson, S.; Thomas, S.M.; Toulmin, C. Food security: The challenge of feeding 9 billion people. Science 2010, 327, 812-818. [CrossRef]

26. Zhang, W.F.; Cao, G.X.; Li, X.L.; Zhang, H.Y.; Wang, C.; Liu, Q.Q.; Chen, X.P.; Cui, Z.L.; Shen, J.B.; Jiang, R.F. Closing yield gaps in China by empowering smallholder farmers. Nature 2016, 537, 671-674. [CrossRef]

27. Mueller, N.D.; Gerber, J.S.; Matt, J.; Ray, D.K.; Navin, R.; Foley, J.A. Closing yield gaps through nutrient and water management. Nature 2013, 490, 254-257. [CrossRef]

28. Chartres, C.J.; Noble, A. Sustainable intensification: Overcoming land and water constraints on food production. Food Secur. 2015, 7, 235-245. [CrossRef]

29. Pingali, P. Westernization of Asian diets and the transformation of food systems: Implications for research and policy. Food Policy 2007, 32, 281-298. [CrossRef]

30. Gerbens-Leenes, P.W.; Nonhebel, S. Consumption patterns and their effects on land required for food. Ecol. Econ. 2002, 42, 185-199. [CrossRef]

31. Rudel, T.K.; Paul, B.; White, D.; Rao, I.M.; Hoek, R.V.D.; Castro, A.; Boval, M.; Lerner, A.; Schneider, L.; Peters, M. LivestockPlus: Forages, sustainable intensification, and food security in the tropics. Ambio 2015, 44, 685-693. [CrossRef]

32. Lam, H.-M.; Remais, J.; Fung, M.-C.; Xu, L.; Sun, S.S.-M. Food supply and food safety issues in China. Lancet 2013, 381, 2044-2053. [CrossRef]

33. de Haen, H.; Réquillart, V. Linkages between sustainable consumption and sustainable production: Some suggestions for foresight work. Food Secur. 2014, 6, 87-100. [CrossRef]

34. Tang, H.J.; Li, Z.M. Study on Per Capita Grain Demand Based on Chinese Reasonable Dietary Pattern. Sci. Agric. Sin. 2012, 45, 2315-2327.

35. Guardian, T. China's Plan to Cut Meat Consumption by $50 \%$ Cheered by Climate Campaigners. Available online: https:/ / www.theguardian.com/world/2016/jun/20/chinas-meat-consumption-climate-change (accessed on 21 November 2018).

36. Xie, H.L.; Wang, P.; Yao, G.R. Exploring the Dynamic Mechanisms of Farmland Abandonment Based on a Spatially Explicit Economic Model for Environmental Sustainability: A Case Study in Jiangxi Province, China. Sustainability 2014, 6, 1260-1282. [CrossRef]

37. Zhang, X.Y.; Zhang, T.Y.; Liu, L.; Ouyang, X.Y. Impact of Soil Heavy Metal Pollution on Food Safety in China. PLoS ONE 2015, 10, e0135182. [CrossRef] 
38. Li, J. Food security: Water shortages loom as northern China's aquifers are sucked dry. Science 2010, 328, 1462-1463.

39. Liu, Y.S.; Fang, F.; Li, Y.H. Key issues of land use in China and implications for policy making. Land Use Policy 2014, 40, 6-12. [CrossRef]

40. Kuyvenhoven, A. International Food Policy Research Institute (2012): 2011 Global Food Policy Report. Food Secur. 2012, 4, 679-681. [CrossRef]

41. Ali, T.; Huang, J.K.; Wang, J.X.; Xie, W. Global footprints of water and land resources through China's food trade. Glob. Food Secur. 2016, 12, 139-145. [CrossRef]

42. Huang, L.M.; Peng, D.L.; Liu, C.W. Changes of the Scale and Structure of Agricultural Laborer and Their Impacts on Food Production-Empirical study on YinshanPo Village, Suizhou City. Asian Agric. Res. 2010, 2, 25-30.

43. Liu, Y.S.; Yang, R.; Li, Y.H. Potential of land consolidation of hollowed villages under different urbanization scenarios in China. J. Geogr. Sci. 2013, 23, 503-512. [CrossRef]

44. Gao, L.W.; Cheng, S.L.; Cao, X.C.; Zhang, D.; Liu, X.J.; Qin, Q.; Liu, Y. An Overview of the Resources and Environmental Issues from Wasted Food in Urban Catering Across China. J. Resour. Ecol. 2013, 4, 337-343.

45. Wang, T. The wasted food can feed 0.3 billion people in China each year. China News, 3 October 2010.

46. Jia, W.; Qin, F. China's grain demand forecast. Food Nutr. China 2013, 19, 40-44.

47. Hammond, R.A.; Laurette, D. A systems science perspective and transdisciplinary models for food and nutrition security. Proc. Natl. Acad. Sci. USA 2012, 109, 12356-12363. [CrossRef]

(C) 2019 by the author. Licensee MDPI, Basel, Switzerland. This article is an open access article distributed under the terms and conditions of the Creative Commons Attribution (CC BY) license (http://creativecommons.org/licenses/by/4.0/). 